\title{
Prescribing medical cannabis: ethical considerations for primary care providers
}

\author{
Aaron Glickman, Dominic Sisti
}

Department of Medical Ethics and Health Policy, University of Pennsylvania, Philadelphia, Pennsylvania, USA

\section{Correspondence to}

Dr Dominic Sisti, Department of Medical Ethics and Health Policy, University of Pennsylvania, Philadelphia, PA 19104, USA;

sistid@pennmedicine.upenn.edu

Received 12 August 2019 Revised 24 November 2019 Accepted 28 November 2019 Published Online First 18 December 2019

Check for updates

(C) Author(s) (or their employer(s)) 2020. No commercial re-use. See rights and permissions. Published by BMJ.

To cite: Glickman A, Sisti D. $J$ Med Ethics

2020;46:227-230.

\section{ABSTRACT}

Medical cannabis is widely available in the USA and legalisation is likely to expand. Despite the increased accessibility and use of medical cannabis, physicians have significant knowledge gaps regarding evidence of clinical benefits and potential harms. We argue that primary care providers have an ethical obligation to develop competency to provide cannabis to appropriate patients. Furthermore, specific ethical considerations should guide the recommendation of medical cannabis. In many cases, these ethical considerations are extensions of well-established principles of beneficence and nonmaleficence, which indicate that providers should recommend cannabis only for conditions that have the strongest evidence base. Additionally, the contested status of cannabis in American culture raises specific issues related to shared decision-making and patient education, as well as continuing clinical education.

\section{INTRODUCTION}

The speed of cannabis legalisation in the USA has been staggering. In 1996, California became the first state to legalise medical cannabis. By 2012, 17 states made medical marijuana legal, and 2 states allowed adult recreational use. By the end of 2020, 33 states and the District of Columbia will have legalised medicinal marijuana, and 11 states will have allowed adult recreational use. ${ }^{12}$ As a result, over two-thirds of states have some form of legalisation, and a majority of Americans live in states with some legal access to marijuana. ${ }^{2}$ Efforts to legalise medical cannabis have succeeded in both state houses and by ballot measure, and two-thirds of Americans support broad legalisation. ${ }^{3}$ After almost a century of prohibition, the question is when-not if-marijuana will be legally available under federal law.

Despite these rapid changes, aspects of the political debate over medicinal cannabis remain entrenched in a discourse that reflects anachronistic moral and political sentiments, rather than evidence-based considerations of how to balance the benefits of medicinal cannabis against potential individual and public health risks. Recent surveys indicate significant knowledge gaps about the effectiveness of medical cannabis among practising physicians, and although many providers believe medical cannabis can be helpful for patients, a minority feel sufficiently informed to make recommendations. ${ }^{45}$ The training pipeline offers little promise of improvement: a recent survey of residents demonstrates that nearly $85 \%$ receive no education in medical school or residency on medical marijuana. ${ }^{6}$ Given the reality of medical cannabis in the USA, we argue primary care providers now have an ethical obligation to develop a level of clinical and ethical competency to enable them to recommend cannabis to their patients when it is indicated.

\section{NORMALISING CANNABIS}

Cannabis occupies a unique social and cultural position in the USA. Marijuana was used as a treatment for a variety of physical and mental ailments as early as the 1850 s. State and federal prohibitions of cannabis, culminating in the 1937 Marijuana Tax Act and the delisting of cannabis in the American Medical Association's US Pharmacopeia in 1942, are deeply interwoven with the history of MexicanAmerican migration. ${ }^{7}$ Since the 1940 s, as the most commonly used illicit drug, cannabis has gained a complex and contradictory status in the USA: it is either harmless or deadly, fully normalised or morally inexcusable.

This social and political history of cannabis prohibition - and the stigma it has perpetuatedcontinues to stall systematic research and regulation of cannabis. The federal Controlled Substances Act (CSA) of 1970 regulates drugs with abuse potential, including manufacturing, supply and use by patients. The US Drug Enforcement Agency (DEA) is tasked by statute to enforce the CSA, and it classifies drugs on schedules I-V based on 'potential for abuse' and 'currently accepted medical use in the USA'. Both of these criteria are undefined in the statute, giving the DEA significant latitude. Since the passage of the CSA, tetrahydrocannabinol (THC) has been listed on schedule I, reserved for drugs with high potential for abuse and no currently accepted medical treatment. Schedule I drugs may not be prescribed for medical use. Investigators conducting research on cannabis plants must obtain the plant through the National Institute on Drug Abuse, which has historically contracted with the University of Mississippi to cultivate cannabis plants for research, although in 2019 the DEA announced plans to allow additional registered marijuana growers. ${ }^{8} 9$ In places where medical marijuana is legal, it can only be 'recommended' rather than prescribed.

Schedule I placement does not reflect an especially high potential for abuse. Rather, the relative medical value differentiates schedule I from schedules II-V. Rescheduling a drug requires either an act of congress or a multistep, convoluted regulatory process involving the attorney general, DEA, the US Department of Health and Human Services, and the US Food and Drug Administration (FDA). ${ }^{10}$ The classification under schedule I effectively is a self-fulfilling prophecy: the restrictions on medical research render the types of large-scale clinical trials required to sufficiently prove medical use to federal 
regulators impossible to achieve, thus keeping the drug on schedule I. ${ }^{11}$ Generally speaking, the scheduling system perpetuates outdated views of problematic drug use. Many substances with high risk for abuse (opioids and opium) are listed in schedule II because specific medications derived from opioids had already been approved (eg, morphine). ${ }^{8}$ Thus, schedule I drugs are historically unique. Because there happened to be no accepted evidence of medical use based on the standards of the FDA in 1970, they were placed in regulatory purgatory.

The approval process for prescription drugs has also changed since the 1970s. Other drugs for pain, nausea and anxiety have been studied and approved by the FDA on the basis of only a few randomised clinical trials. Often serious side effects are only discovered years after approval. The federal regulatory bar for cannabis appears to be much higher than other medications. And so the debate over medical cannabis raises a larger question of what level of evidence is sufficient to prescribe a drug widely and what level of possible toxicity is acceptable. Nevertheless, the double standard has no ethical or empirical basis; it serves as a barrier to clear reasoning about the risks and benefits of medical cannabis.

The DEA's failure to reschedule cannabis is out of step with medical literature. ${ }^{11-14}$ While there is some debate about the robustness of evidence, a consensus is emerging that cannabis likely has therapeutic benefits for patients with chronic pain, chemotherapy-induced nausea and vomiting, and multiple sclerosis symptoms. ${ }^{13}{ }^{14}$ The evidence base includes randomised control trials, systematic reviews and meta-analyses. ${ }^{14}$ The FDA has approved cannabis-based products for some of these purposes. When appropriate, adult patients should have ready access to cannabis to treat these conditions as they would any other medicine.

\section{RECOGNISING RISK}

Cannabis use carries certain risks. As a psychoactive drug, effects on behavioural health are especially important to recognise. In particular, cannabis use is associated with increased incidence of psychosis in a dose-dependent manner, major depressive disorder, bipolar disorder and anxiety disorders. ${ }^{15}$ For children and adolescents, the clinical and ethical trade-offs are more complex; the younger the individual, the higher the risk for cannabis dependence or adverse outcomes. ${ }^{16}$

Individuals with mental health disorders disproportionately use drugs like cannabis, and it is common for people with drug abuse or dependency disorders to have co-occurring mental health disorders. ${ }^{17}$ People with psychosis spectrum disorders frequently self-medicate with marijuana, ${ }^{18}{ }^{19}$ a practice linked to greater risk of drug dependence, making its use both a selfadministered treatment and a potential cause of psychosis. ${ }^{20}$ The causal relationship between cannabis and mental illness remains unclear, likely multidirectional, and subject to confounding. ${ }^{21}$

There are several possible and likely interconnected causes of these associations. First, substance abuse may be a risk factor for developing mental illness. Second, mental illness may be a risk factor for developing substance abuse disorder. Third, there may be an overlap of predisposing risk factors to both conditions, like genetic vulnerability and environmental stress. ${ }^{22}$ These are not mutually exclusive causal relationships, and the multiple associations found between cannabis and severe mental health disorders require prudence when recommending cannabis, especially for young adults and patients with other risk factors.

Problematic cannabis use, such as addiction and habitual use that interfere with daily life, while infrequent among cannabis users, is also a risk. In particular, there is evidence that initiating cannabis use early in childhood significantly increases the risk of problematic cannabis consumption later in life. ${ }^{23}$ There appears to be a dose-response across all age cohorts; that is, increased frequency and heavy usage are associated with a greater chance of problem cannabis use later in life. ${ }^{24}$

For pregnant women and neonates, there is evidence that smoking marijuana during pregnancy can increase the chance of low birth rate. However, observational studies of cannabis use during pregnancy note a confounding of cannabis with tobacco and alcohol use. While researchers have used a variety of statistical techniques in an effort to parse out the effect of cannabis, the data are limited to smoked cannabis. As a result, there is little evidence that THC itself is associated with severe complications in neonates. Rather, the primary finding is that smoking cannabis increases the risk of low birth weight. ${ }^{22}$

There are other somatic health concerns regarding respiratory function, risk for cancer, cardiovascular health and accidental injury associated with cannabis. However, it remains to be seen how much of the risk factor is specific to how cannabis is ingested, that is, inhaled as smoke, ingested in food or consumed in other forms.

The range of modalities of cannabis consumption, the variety of strains, and varying cannabinoid and terpene concentrations all complicate assessments of the risks and benefits of cannabis use. It may instead be useful to conceptualise cannabis as a class of therapies, rather than a single drug with one specific active ingredient. The expansion of legalised cannabis has yielded a range of options for recreational and medicinal consumers. Cannabis flower can be smoked; THC can be concentrated into pills, vaporised from waxes and tinctures, or added to food and drinks. Some ingestion methods yield far more potent products in terms of THC concentration, as well as different ratios of THC to cannabidiol (CBD) and other compounds. It is likely that each modality offers a range of therapeutic effects.

\section{ETHICAL CONSIDERATIONS}

The ethical principles guiding patient care and treatment with cannabis are similar to any other medication. These include ensuring a favourable benefit to risk ratio, fully informed consent, and careful monitoring for safety and side effects. However, there are also a few additional ethical considerations that become salient to cannabis use that are related to social context and lingering misconceptions. The principles of biomedical ethics--beneficence and nonmaleficence, respect for autonomy, and justice--can help to guide cannabis care.

To uphold the principles of beneficence and nonmaleficence, providers should recommend cannabis only for conditions where the evidence base is well-established. These include conditions such as chronic pain, nausea, and symptoms of multiple sclerosis. As evidence accrues that cannabis is safe and effective for other conditions and subpopulations, primary care providers should remain open and willing to prescribe it for different indications. It is important to note that states differ in what they consider legally 'qualifying' conditions. The variation in recommendation patterns is not well understood, and recent evidence suggests that $85.5 \%$ of cannabis recommendations were for conditions with substantial and conclusive evidence of clinical efficacy. ${ }^{25}$ However, in some states, some conditions such as post-traumatic stress disorder are considered qualifying despite a paucity of evidence for clinical efficacy to date. ${ }^{26}$

Because specific state laws and regulations may not reflect the current body of evidence, legal and ethical uses of cannabis may 
at times be in conflict. While it may be illegal to recommend cannabis for conditions other than those specified by state law, it is ethically justifiable for providers to do so if available evidence supports cannabis use for a particular patient's condition. Similarly, for conditions where the evidence of effectiveness remains equivocal, providers should not accept legality as the ethical foundation for recommending cannabis.

Many patients will have prior experience with cannabis. Providers should take this experience seriously and engage in a patient-guided, shared decision-making process. The provider's ability to strike a balance between population-level evidence and the experience of an individual patient is part of the art of medicine; it should not be difficult to apply similar dialectical logic when treating with medical cannabis. In some cases, providers may ethically recommend medical cannabis for 'off-label' use for low-risk patients with prior experience. However, given significant changes in purity and potency of marijuana, a patient's past cannabis use should not be determinative when formulating a new treatment course. Furthermore, physicians must weigh prior patient experience against patient-specific risks (eg, pregnancy or underlying mental health concerns) and available evidence and must be willing to counsel discontinuation of cannabis use.

Primary care providers must recognise the differential clinical effects and adverse risks of cannabis on various subpopulations. Cannabis is differentially effective for chronic pain and nausea in adults and in children. Based on the literature regarding the risks and benefits of cannabis, the decision to recommend cannabis to young adults (under the age of 25 years) ought to pass a much higher evidentiary test than for older patients. This is not to say that all children should be denied access to cannabis, but the greater risk of mental health consequences requires caution.

Primary care providers should also educate patients about safer ways to use cannabis. First, the dose dependency of adverse effects of THC suggests a conservative approach. While much of the research on dosage is underdeveloped, providers should recommend use of low potency THC products first. This is especially important, given the increasing average potency of cannabis products over time and the increased availability of highly concentrated synthesised products. Second, given the confounding of smoking tobacco with THC consumption, providers should recommend against smoked cannabis under most circumstances. Third, because cannabis is available through both regulated and unregulated markets, providers must take into account the different ways patients may obtain cannabis and counsel against seeking unregulated supplies. Fourth, attention should be paid to CBD content in cannabis products. CBD is a non-intoxicating component of cannabis, but a high CBD content results in lower THC content. As a result, many products have little or no CBD, in favour of a higher concentration of THC. An emerging literature suggests that higher CBD content in cannabis products may be protective against the risk of psychosis and cognitive impairment. ${ }^{16}$ While more research is needed to fully understand the actual extent to which CBD protects against adverse side effects of THC, the evidence to date and the principle of nonmaleficence suggest that physicians should in general consider cannabis products that contain a relatively high $\mathrm{CBD}$ to THC ratio, unless otherwise indicated.

The imperative to reduce the risk of cannabis consumption also requires providers to understand the various modalities of cannabis consumption. As noted earlier, certain methods of ingestion may alter the potency and metabolism of cannabinoids. At the moment, it seems reasonable to suggest providers advise against excessive smoking of cannabis or the use of especially highly concentrated tinctures, waxes, and "shatter"-except in patients with significant experience or serious chronic pain-in favour of lower-potency options.

The widespread outbreak of vaping-related illnesses in the US, which has been linked to several deaths and over 1,000 lung injury cases, demonstrates the need to pay close attention to how patients use cannabis and where they procure it. The connection between vaping and lung injury appears to be connected to vitamin $\mathrm{E}$ acetate, an additive found in unregulated THC cartridges. Providers should follow guidance from the Centers for Disease Control regarding vaping and should be knowledgeable about the formulations of various concentrates available in their state.

Clinicians are expected to remain current about newly approved medications, new screening guidelines and diagnostic methods, and the reclassification of therapies as ineffective or harmful. For example, primary care providers are expected to update management of diabetic patients in line with the regularly updated and adjusted American Diabetes Association's 'Standards of Medical Care in Diabetes'. ${ }^{27}$ A similar duty to engage in self-education applies to cannabis. Without a comprehensive understanding of what is available to patients in local contexts, it is impossible to manage a treatment plan, as physicians would do with any other drug for a chronic or acute condition.

In the USA, no single accepted medical body has set broad guidelines for cannabis use, which complicates the task of continuing education. However, medical cannabis organisations, such as the Society of Cannabis Clinicians, do offer curricula that can serve as a reasonable starting place for many practitioners.

\section{CONCLUSION}

Several of the ethical imperatives for managing medical cannabis are direct imports from existing principles, including weighing costs and benefits and patient-centred decision-making. However, the unique legal and social status of cannabis also yields several particular considerations. These issues include an understanding that what the state considers a qualifying condition may not map to clinical evidence and a recognition that cannabis is not a simple pill to be prescribed but a complex class of therapies that must be managed and adjusted in collaboration with individual patients.

Like any other medicine, decisions about cannabis should not be subject to providers' social or political biases or anecdotal evidence. At the same time, providers should judiciously integrate the knowledge of their experienced patients as they develop patient-centred treatment plans for any number of conditions for which medical cannabis is beneficial. Primary care providers now have an ethical obligation to develop the requisite expertise to provide cannabis to patients who may benefit from it.

Acknowledgements Dominic Sisti acknowledges and thanks the Thomas Scattergood Foundation for its support.

Contributors AG conducted research secondary research, drafted significant portions of the article and made substantive edits. DS drafted significant portions of the article, made substantive edits and provided feedback to guide the research plan.

Funding The authors have not declared a specific grant for this research from any funding agency in the public, commercial or not-for-profit sectors.

Competing interests None declared.

Patient consent for publication Not required.

Provenance and peer review Not commissioned; externally peer reviewed.

Data availability statement There are no data in this work.

\section{ORCID iD}

Dominic Sisti 0000-0002-2282-9253 


\section{REFERENCES}

1 Carliner H, Brown QL, Sarvet AL, et al. Cannabis use, attitudes, and legal status in the U.S.: a review. Prev Med 2017;104:13-23.

2 National Conference of State Legislatures. State medical marijuana laws. Available: http://www.ncsl.org/research/health/state-medical-marijuana-laws.aspx

3 McCarthy J. Two in three Americans now support legalizing marijuana, 2019. Available: https://news.gallup.com/poll/243908/two-three-americans-supportlegalizing-marijuana.aspx

4 Philpot LM, Ebbert JO, Hurt RT. A survey of the attitudes, beliefs and knowledge about medical cannabis among primary care providers. BMC Fam Pract 2019;20(1):17.

5 Braun IM, Wright A, Peteet J, et al. Medical oncologists' beliefs, practices, and knowledge regarding marijuana used therapeutically: a nationally representative survey study. J Clin Oncol 2018;36(19):1957-62.

6 Evanoff AB, Quan T, Dufault C, et al. Physicians-in-training are not prepared to prescribe medical marijuana. Drug Alcohol Depend 2017;180:151-5.

7 Bonnie RJ, Whitebread CH. The marijuana conviction : a history of marijuana prohibition in the United States. New York: Lindesmith Center, 1999.

8 Mead A. The legal status of cannabis (marijuana) and cannabidiol (CBD) under U.S law. Epilepsy Behav 2017;70(Pt B):288-91.

9 National Institute on Drug Abuse. NIDA's role in providing marijuana for research, 2019. Available: https://www.drugabuse.gov/drugs-abuse/marijuana/nidas-role-inproviding-marijuana-research [Accessed 6 Nov 2019].

10 Hudak J, Wallack G. How to reschedule marijuana, and why it's unlikely anytime soon, 2015. Available: https://www.brookings.edu/blog/fixgov/2015/02/13/how-to reschedule-marijuana-and-why-its-unlikely-anytime-soon/

11 Nutt DJ, King LA, Nichols DE. Effects of schedule I drug laws on neuroscience research and treatment innovation. Nat Rev Neurosci 2013;14(8):577-85.

12 Zajicek JP, Hobart JC, Slade A, et al. Multiple sclerosis and extract of cannabis: results of the MUSEC trial. J Neurol Neurosurg Psychiatry 2012;83(11):1125-32.

13 Whiting PF, Wolff RF, Deshpande $S$, et al. Cannabinoids for medical use: a systematic review and meta-analysis. JAMA 2015:313(24):2456-73.

14 National Academies of Sciences Engineering and Medicine (US). Committee on the Health Effects of Marijuana: an Evidence Review and Research Agenda. In: The health effects of cannabis and cannabinoids: the current state of evidence and recommendations for research. Washington, DC: The National Academies Press, 2017
15 Lowe DJE, Sasiadek JD, Coles AS, et al. Cannabis and mental illness: a review. Eur Arch Psychiatry Clin Neurosci 2019;269(1):107-20.

16 Englund A, Freeman TP, Murray RM, et al. Can we make cannabis safer? Lancet Psychiatry 2017;4(8):643-8.

17 Janaki Bose SLH, Lipari RN, Park-Lee E. Key substance use and mental health indicators in the United States: results from the 2017 national survey on drug use and health. Rockville, MD: Center for Behavioral Health Statistics and Quality, Substance Abuse and Mental Health Services Administration, 2018.

18 Bonn-Miller MO, Boden MT, Bucossi MM, et al. Self-reported cannabis use characteristics, patterns and helpfulness among medical cannabis users. Am J Drug Alcohol Abuse 2014;40(1):23-30.

19 Sarvet AL, Wall MM, Keyes KM, et al. Self-Medication of mood and anxiety disorders with marijuana: higher in states with medical marijuana laws. Drug Alcohol Depend 2018;186:10-15.

20 Marconi A, Di Forti M, Lewis CM, et al. Meta-Analysis of the association between the level of cannabis use and risk of psychosis. Schizophr Bull 2016;42(5):1262-9.

21 McLaren JA, Silins E, Hutchinson D, et al. Assessing evidence for a causal link between cannabis and psychosis: a review of cohort studies. Int I Drug Policy 2010;21(1):10-19.

22 Gunn JKL, Rosales CB, Center KE, et al. Prenatal exposure to cannabis and maternal and child health outcomes: a systematic review and meta-analysis. BMJ Open 2016;6(4):e009986.

23 Blanco C, Hasin DS, Wall MM, et al. Cannabis use and risk of psychiatric disorders: prospective evidence from a US national longitudinal study. JAMA Psychiatry 2016;73(4):388-95.

24 Cougle JR, Hakes JK, Macatee RJ, et al. Probability and correlates of dependence among regular users of alcohol, nicotine, cannabis, and cocaine: concurrent and prospective analyses of the National epidemiologic survey on alcohol and related conditions. J Clin Psychiatry 2016:77(4):e444-50.

25 Boehnke KF, Gangopadhyay S, Clauw DJ, et al. Qualifying conditions of medical cannabis license holders in the United States. Health Aff 2019:38(2):295-302.

26 O'Neil ME, Nugent SM, Morasco BJ, et al. Benefits and harms of plant-based cannabis for posttraumatic stress disorder: a systematic review. Ann Intern Med 2017:167(5):332-40.

27 Anon. Summary of Revisions: Standards of Medical Care in Diabetes-2018. Diabetes Care 2018:41(Suppl 1):S4-6. 